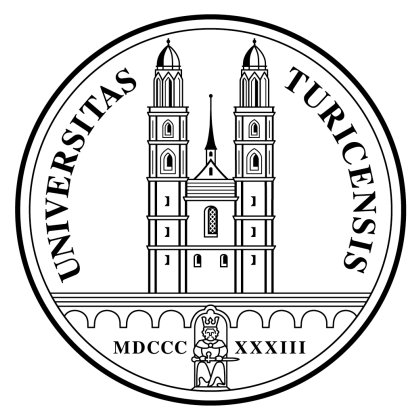

Institute for Empirical Research in Economics

University of Zurich

Working Paper Series

ISSN 1424-0459

Working Paper No. 173

The Value of Autonomy:

Evidence from the Self-Employed in 23 Countries

Matthias Benz and Bruno S. Frey

November 2003 


\title{
The Value of Autonomy: \\ Evidence from the Self-Employed in 23 Countries
}

\author{
MatThias BenZ AND BRUno S. FREY* \\ UNIVERSITY OF ZURICH
}

October 31, 2003

\begin{abstract}
The self-employed are substantially more satisfied with their work than employed persons. We document this relationship for 23 countries and show that the higher job satisfaction can directly be attributed to the greater autonomy that self-employed persons enjoy. "Being your own boss" seems to provide non-pecuniary benefits from work that point to the existence of procedural utility: autonomy is valued beyond outcomes as a good decision-making procedure. The results hold not only for Western European, North American and former communist Eastern European countries, but largely also for countries with a nonwestern cultural background. (91 words)
\end{abstract}

Keywords: self-employment, autonomy, job satisfaction, procedural utility JEL-Codes: D00, M54, J23, J81, L22

\footnotetext{
* Institute for Empirical Research in Economics, University of Zurich, Bluemlisalpstr. 10, CH-8006 Zurich; Tel. +41 163437 31, Fax.+41163449 07, email: matbenz@iew.unizh.ch, bsfrey@iew.unizh.ch. We would like to thank Geoffrey Brennan, James Buchanan, Bob Cooter, Christoph Engel, Egon Franck, Henry Hansmann, Daniel Kahneman, Simon Luchinger, Stephan Meier, Dennis Mueller, Alois Stutzer, Todd Zenger, and participants at research seminars in Zurich, Aarhus and Princeton for helpful comments.
} 


\section{Introduction}

Self-employed people are considerably more satisfied with their work than people employed in organizations. Higher job satisfaction among the self-employed has been consistently found in numerous European countries (see e.g. Blanchflower and Oswald 1998, Blanchflower 2000, Frey and Benz 2003), in the United States (Kawaguchi 2002, Hundley 2001) and Canada (Finnie, LaPorte and Rivard 2003). But also studies looking at revealed behavior have documented benefits of self-employment. For example, self-employed persons are willing to work for a lower wage (Hamilton 2000), and they accept lower risk-adjusted returns on their entrepreneurial investments (Moskovitz and Vissing-Jorgensen 2002). Compensating wage and return differentials thus indicate that people forego considerable material gains in order to be self-employed. But why?

In this paper, we investigate potential explanations for these observations, based on an analysis of why the self-employed are happier with their jobs. We document job satisfaction differences between self-employed and employed persons for an extended set of 23 countries, finding that in essentially all countries considered the self-employed are more satisfied with their work. We then examine the reasons behind the job satisfaction differential by attributing it to several important work aspects. The results indicate that the greater autonomy of selfemployed persons is largely responsible for their particular job satisfaction; in Western European, North American and Eastern European countries, it fully explains the job satisfaction differential between self-employed and employed persons. In contrast, other work aspects like pay, job security or opportunities for advancement cannot account for the observed differences. The findings thus confirm the widely held notion that greater freedom in the work environment, such as the opportunity to "be your own boss", is an important source of happiness at work. ${ }^{1}$

Our analysis can provide novel insights in three respects. First, it presents for the first time direct evidence that people value autonomy. ${ }^{2}$ Given that job satisfaction is a useful approximation for the utility from work, it follows that the opportunity to be independent and self-determined constitutes an important nonpecuniary work benefit, at least for self-

\footnotetext{
${ }^{1}$ Hamilton (2000: 628) e.g. refers to this explanation in interpreting his results: "For most entrepreneurs, the empirical evidence [...] is consistent with the notion that self-employment offers significant nonpecuniary benefits, such as 'being your own boss'." Moskovitz and Vissing-Jorgensen (2002: 772f.) also regard the value of autonomy as a potential explanation of their findings.

${ }^{2}$ There are two previous studies showing that the higher job satisfaction of self-employed persons is strongly related to their greater autonomy. However, these studies present evidence only for a limited number of countries, see Hundley (2001) for the United States and Frey and Benz (2003) for Great Britain.
} 
employed persons. Second, the results point to the existence of "procedural utility" (Frey, Benz and Stutzer 2003): autonomy is not valued because it leads to better instrumental outcomes, like higher income, but rather as a good decision making procedure in itself. Third, by studying not only countries from Western Europe and North America, but also from Eastern Europe and from non-western cultures, we are able to test whether autonomy is valued differently in different cultures. In social sciences outside economics, it is often argued that autonomy of choice may be important to people in "individualistic" western cultures, but not in more "collectivistic" non-western cultural contexts, like Asia (Iyengar and Lepper 1999, Schwartz 2000, Markus and Kitayama 1991). Our results do not support this view. Rather, we find that self-employed persons derive greater satisfaction from their work also in non-western countries, and to a considerable extent because they value the autonomy associated with self-employment.

The paper is organized as follows: section 2 presents the data used, section 3 contains the empirical analysis, and section 4 offers a discussion of the results and their implications.

\section{Data}

The empirical analysis is based on the International Social Survey Program 1997 (ISSP97), a survey conducted among 16'000 individuals in 23 countries. Although the ISSP97 is less comprehensive than established panels, such as the National Longitudinal Survey of Youth, the British Household Panel Survey or the German Socio-Economic Panel, it is nevertheless well suited for the purposes of this paper. On the one hand, it includes a much broader set of countries than has been investigated in previous studies (e.g. Blanchflower 2000), combining data from different geographical and cultural regions, like Western Europe (Germany, Great Britain, France, Italy, Portugal, Switzerland, Denmark, Norway, Sweden), North America (United States of America, Canada), Eastern Europe (Hungary, Czech Republic, Poland, Bulgaria, Slovenia, Russia) and a residual group of "non-western" countries (Japan, New Zealand, Cyprus, Israeli Jews and Arabs, and the less developed countries Bangladesh and the Philippines). ${ }^{3}$ On the other hand, the ISSP97 contains information on all the basic variables required for the empirical analysis; the individuals surveyed were asked some identical questions on their work life, which makes meaningful comparisons of the results possible across the countries under consideration.

\footnotetext{
${ }^{3}$ The ISSP97 originally included two more countries, Spain and the Netherlands, which cannot be used in the empirical analysis because information on self-employment status is missing.
} 
Self-reported job satisfaction is used as the dependent variable in the empirical analysis. It is assessed with the following question: "How satisfied are you in your (main) job?" Individuals are asked to state their job satisfaction on a scale from 1 ("completely satisfied") to 7 (“completely dissatisfied"); for convenience, answers are recoded so that a value of 7 reflects the highest job satisfaction category and a value of 1 the lowest. The main explanatory variable consists of information on individuals' self-employment status. The dummy 'selfemployed' takes on the value 1 when individuals state that they are self-employed, and is 0 when people in the workforce are employed by an organization ("In your (main) job, are you an employee or self-employed?"). The ISSP97 moreover contains information on some important control variables: personal work income (assessed as income categories or as absolute values, depending on the country), the average number of hours worked per week (including overtime), education (measured in years of schooling), and the age and gender of individuals. Data on occupation and industry is not available for the empirical analysis, as this information is missing for a substantial number of countries.

A potential drawback of the ISSP97 is that it only contains a limited number of control variables, and that people are surveyed only once. These shortcomings, however, are compensated by a set of unique survey questions that can be used to perform a direct empirical test of the reasons behind the self-employment - job satisfaction relationship. Both self-employed and employed individuals are asked to rate several important dimensions of their work: "For each of the following statements about your main job, how much do you agree or disagree that it applies to your job?": (i) "my job is secure”, (ii) "my income is high", (iii) "my opportunities for advancement are high", (iv) "my job is interesting", (v) "I can work independently", (vi) "in my job I can help other people" and (vii) "my job is useful to society". Individuals give an evaluation for each of these work aspects on a scale from 1 ("strongly disagree") to 5 ("strongly agree"). The respective answers are used here to investigate the reasons for the higher job satisfaction among the self-employed. In a first step, job satisfaction regressions are estimated, including the variable on self-employment and control variables. In a second step, an examination is made on how the (presumably positive) coefficient on the variable "self-employed" changes when individuals" evaluations of the different job aspects are entered into the regression. If, for example, the inclusion of the variable on "job security" leaves the size and the significance of the self-employment coefficient unaffected, it follows that differences in perceived job security are not responsible for the differences in job satisfaction between self-employed and employed persons. If, in contrast, the coefficient is lowered to zero, one is led to conclude that differential job security 
is important in explaining why the self-employed are more satisfied with their jobs. The same procedure can be applied to every job aspect, indicating which work characteristics account for higher job satisfaction among the self-employed. ${ }^{4}$

\section{Empirical Analysis}

\subsection{Basic results}

Table 1 presents the basic results on the relationship between self-employment and job satisfaction in the 23 countries considered. In the two left-hand columns of the table, descriptive statistics are reported for each country, indicating the differences in average job satisfaction between self-employed and employed people. In the two right-hand columns, the effects of self-employment on job satisfaction are evaluated in multivariate ordered-logitregressions. Besides the dummy "self-employed", for which the estimated coefficient is reported in table 1, a first specification also includes control variables on work income, weekly hours worked, weekly hours worked squared, education, education squared, age, age squared and gender ("regression including compensating variables"). In a second specification, the same regressions are run without the variables on income and working hours ("regression excluding compensating variables"). ${ }^{5}$ The reasons for this are, on the one hand, that information on work income is missing for many individuals, particularly for selfemployed people. The sample sizes for the second specification can thus be substantially higher, which may reduce potential estimation biases. On the other hand, wages are the compensating dimension for non-pecuniary work benefits in a well functioning labor market. If benefits from being self-employed are already reflected in a compensating wage differential, the inclusion of the income and working hours variables into the regression can lead to an overestimation of the job satisfaction differences between self-employed and employed people. By using two specifications, the robustness of the results can be evaluated without having to make assumptions on whether the labor market in a country is sufficiently competitive or, in contrast, systematic labor market rents exist.

\footnotetext{
${ }^{4}$ Note that individual heterogeneity is unlikely to bias this empirical test. If e.g. intrinsically optimistic people report higher job satisfaction regardless of their employment situation, and at the same time are more likely to be self-employed, a positive relationship between self-employment and job satisfaction might merely reflect personality differences. However, it would then also seem likely that self-employed people evaluate every characteristic of their work in a positive way, i.e., that the higher job satisfaction of the self-employed is explained by every single aspect of their job. The empirical test applied here importantly hinges on the idea that some work characteristics explain the self-employment - job satisfaction differential, while others do not.

${ }^{5}$ The estimation results for the control variables are not shown in table 1 for reasons of space, but they can be obtained from the authors.
} 
Table 1: Self-Employment and Job Satisfaction in 23 Countries

Dependent Variable: Job Satisfaction

\begin{tabular}{|c|c|c|c|c|}
\hline \multirow[b]{2}{*}{$\begin{array}{l}\text { Region / } \\
\text { Country }\end{array}$} & \multicolumn{2}{|c|}{$\begin{array}{l}\text { Job satisfaction } \\
\quad(\text { means })\end{array}$} & \multicolumn{2}{|c|}{$\begin{array}{l}\text { Coefficient on the variable "self-employed" } \\
\text { (ordered-logit-regressions) }\end{array}$} \\
\hline & Self-employed & Employed & $\begin{array}{l}\text { Regression including } \\
\text { "compensating" } \\
\text { variables } \\
\text { (I) }\end{array}$ & $\begin{array}{l}\text { Regression excluding } \\
\text { "compensating" } \\
\text { variables } \\
\text { (II) }\end{array}$ \\
\hline \multicolumn{5}{|l|}{ Western Europe } \\
\hline Germany & $\begin{array}{c}5.52 \\
(\mathrm{~N}=93)\end{array}$ & $\begin{array}{c}5.12 \\
(\mathrm{~N}=892)\end{array}$ & $\begin{array}{l}0.746 * * \\
(\mathrm{~N}=888)\end{array}$ & $\begin{array}{l}0.701 * * \\
(\mathrm{~N}=911)\end{array}$ \\
\hline Great Britain & $\begin{array}{c}5.40 \\
(\mathrm{~N}=82)\end{array}$ & $\begin{array}{c}5.08 \\
(\mathrm{~N}=485)\end{array}$ & $\begin{array}{c}0.514^{\circ} \\
(\mathrm{N}=504)\end{array}$ & $\begin{array}{c}0.579 * \\
(\mathrm{~N}=560)\end{array}$ \\
\hline France & $\begin{array}{c}5.50 \\
(\mathrm{~N}=34)\end{array}$ & $\begin{array}{c}5.06 \\
(\mathrm{~N}=653)\end{array}$ & $\begin{array}{l}0.957 * * \\
(\mathrm{~N}=656)\end{array}$ & $\begin{array}{c}0.796 * \\
(\mathrm{~N}=687)\end{array}$ \\
\hline Italy & $\begin{array}{c}5.45 \\
(\mathrm{~N}=142)\end{array}$ & $\begin{array}{c}5.06 \\
(\mathrm{~N}=321)\end{array}$ & $\begin{array}{l}0.895 * * \\
(\mathrm{~N}=289)\end{array}$ & $\begin{array}{l}0.700 * * \\
(\mathrm{~N}=460)\end{array}$ \\
\hline Portugal & $\begin{array}{c}5.24 \\
(\mathrm{~N}=226)\end{array}$ & $\begin{array}{c}5.14 \\
(\mathrm{~N}=662)\end{array}$ & $\begin{array}{c}0.267 \\
(\mathrm{~N}=846)\end{array}$ & $\begin{array}{c}0.122 \\
(\mathrm{~N}=853)\end{array}$ \\
\hline Switzerland & $\begin{array}{c}5.87 \\
(\mathrm{~N}=228)\end{array}$ & $\begin{array}{c}5.43 \\
\left(\mathrm{~N}=1^{\prime} 505\right)\end{array}$ & $\begin{array}{c}0.682 * * \\
\left(\mathrm{~N}=1^{\prime} 442\right)\end{array}$ & $\begin{array}{c}0.773 * * \\
\left(\mathrm{~N}=1^{\prime} 725\right)\end{array}$ \\
\hline Denmark & $\begin{array}{c}5.84 \\
(\mathrm{~N}=45)\end{array}$ & $\begin{array}{c}5.68 \\
(\mathrm{~N}=593)\end{array}$ & $\begin{array}{c}0.584 \\
(\mathrm{~N}=581)\end{array}$ & $\begin{array}{c}0.349 \\
(\mathrm{~N}=635)\end{array}$ \\
\hline Norway & $\begin{array}{c}5.43 \\
(\mathrm{~N}=157)\end{array}$ & $\begin{array}{c}5.20 \\
\left(\mathrm{~N}=1^{\prime} 456\right)\end{array}$ & $\begin{array}{c}0.374 * \\
(\mathrm{~N}=1 ' 304)\end{array}$ & $\begin{array}{c}0.335^{*} \\
(\mathrm{~N}=1 ' 395)\end{array}$ \\
\hline Sweden & $\begin{array}{c}5.70 \\
(\mathrm{~N}=86)\end{array}$ & $\begin{array}{c}5.20 \\
(\mathrm{~N}=728)\end{array}$ & $\begin{array}{l}1.049 * * \\
(\mathrm{~N}=728)\end{array}$ & $\begin{array}{l}0.968 * * \\
(\mathrm{~N}=768)\end{array}$ \\
\hline \multicolumn{5}{|l|}{ North America } \\
\hline USA & $\begin{array}{c}5.63 \\
(\mathrm{~N}=112)\end{array}$ & $\begin{array}{c}5.32 \\
(\mathrm{~N}=714)\end{array}$ & $\begin{array}{c}0.405^{\circ} \\
(\mathrm{N}=713)\end{array}$ & $\begin{array}{c}0.414 * \\
(\mathrm{~N}=822)\end{array}$ \\
\hline Canada & $\begin{array}{c}5.44 \\
(\mathrm{~N}=98)\end{array}$ & $\begin{array}{c}5.06 \\
(\mathrm{~N}=528)\end{array}$ & $\begin{array}{c}0.500^{*} \\
(\mathrm{~N}=470)\end{array}$ & $\begin{array}{c}0.512 * \\
(\mathrm{~N}=516)\end{array}$ \\
\hline \multicolumn{5}{|l|}{ Eastern Europe } \\
\hline Hungary & $\begin{array}{c}5.05 \\
(\mathrm{~N}=93)\end{array}$ & $\begin{array}{c}4.77 \\
(\mathrm{~N}=525)\end{array}$ & $\begin{array}{c}0.041 \\
(\mathrm{~N}=510)\end{array}$ & $\begin{array}{c}0.462 * \\
(\mathrm{~N}=618)\end{array}$ \\
\hline Czech Republic & $\begin{array}{c}5.63 \\
(\mathrm{~N}=54)\end{array}$ & $\begin{array}{c}5.06 \\
(\mathrm{~N}=467)\end{array}$ & $\begin{array}{c}1.026^{\circ} \\
(\mathrm{N}=360)\end{array}$ & $\begin{array}{l}0.889 * * \\
(\mathrm{~N}=516)\end{array}$ \\
\hline Poland & $\begin{array}{c}5.20 \\
(\mathrm{~N}=149)\end{array}$ & $\begin{array}{c}5.08 \\
(\mathrm{~N}=392)\end{array}$ & $\begin{array}{c}0.267 \\
(\mathrm{~N}=479)\end{array}$ & $\begin{array}{c}0.296 \\
(\mathrm{~N}=517)\end{array}$ \\
\hline Bulgaria & $\begin{array}{c}5.53 \\
(\mathrm{~N}=53)\end{array}$ & $\begin{array}{c}4.96 \\
(\mathrm{~N}=405)\end{array}$ & $\begin{array}{l}0.873 * * \\
(\mathrm{~N}=400)\end{array}$ & $\begin{array}{l}0.978 * * \\
(\mathrm{~N}=448)\end{array}$ \\
\hline Slovenia & $\begin{array}{c}5.08 \\
(\mathrm{~N}=49)\end{array}$ & $\begin{array}{c}4.95 \\
(\mathrm{~N}=458)\end{array}$ & $\begin{array}{c}0.116 \\
(\mathrm{~N}=395)\end{array}$ & $\begin{array}{c}0.235 \\
(\mathrm{~N}=486)\end{array}$ \\
\hline Russia & $\begin{array}{c}4.95 \\
(\mathrm{~N}=86)\end{array}$ & $\begin{array}{c}4.84 \\
(\mathrm{~N}=773)\end{array}$ & $\begin{array}{c}0.306 \\
(\mathrm{~N}=671)\end{array}$ & $\begin{array}{c}0.216 \\
(\mathrm{~N}=817)\end{array}$ \\
\hline \multicolumn{5}{|c|}{$\begin{array}{l}\text { Other, "non-western" } \\
\text { countries }\end{array}$} \\
\hline Japan & $\begin{array}{c}5.17 \\
(\mathrm{~N}=195)\end{array}$ & $\begin{array}{c}4.74 \\
(\mathrm{~N}=517)\end{array}$ & $\begin{array}{c}0.391^{\circ} \\
(\mathrm{N}=559)\end{array}$ & $\begin{array}{c}0.382 * \\
(\mathrm{~N}=679)\end{array}$ \\
\hline New Zealand & $\begin{array}{c}5.32 \\
(\mathrm{~N}=66)\end{array}$ & $\begin{array}{c}5.44 \\
(\mathrm{~N}=236)\end{array}$ & $\begin{array}{c}-0.173 \\
(\mathrm{~N}=276)\end{array}$ & $\begin{array}{c}-0.107 \\
(\mathrm{~N}=283)\end{array}$ \\
\hline
\end{tabular}




\section{Table 1 continued}

\begin{tabular}{|c|c|c|c|c|}
\hline Cyprus & $\begin{array}{c}6.08 \\
(\mathrm{~N}=153)\end{array}$ & $\begin{array}{c}5.50 \\
(\mathrm{~N}=423)\end{array}$ & $\begin{array}{l}1.225^{* *} \\
(\mathrm{~N}=557)\end{array}$ & $\begin{array}{l}1.182 * * \\
(\mathrm{~N}=564)\end{array}$ \\
\hline Israel (Jews) & $\begin{array}{c}5.91 \\
(\mathrm{~N}=93)\end{array}$ & $\begin{array}{c}5.24 \\
(\mathrm{~N}=364)\end{array}$ & $\begin{array}{c}0.602 * \\
(\mathrm{~N}=383)\end{array}$ & $\begin{array}{l}1.004 * * \\
(\mathrm{~N}=454)\end{array}$ \\
\hline Israel (Arabs) & $\begin{array}{c}5.72 \\
(\mathrm{~N}=46)\end{array}$ & $\begin{array}{c}5.36 \\
(\mathrm{~N}=134)\end{array}$ & $\begin{array}{c}1.091 * \\
(\mathrm{~N}=158)\end{array}$ & $\begin{array}{l}0.951 * * \\
(\mathrm{~N}=174)\end{array}$ \\
\hline Bangladesh & $\begin{array}{c}5.43 \\
(\mathrm{~N}=53)\end{array}$ & $\begin{array}{c}5.17 \\
(\mathrm{~N}=421)\end{array}$ & $\begin{array}{c}0.799 * \\
(\mathrm{~N}=463)\end{array}$ & $\begin{array}{l}0.897 * * \\
(\mathrm{~N}=474)\end{array}$ \\
\hline The Philippines & $\begin{array}{c}5.71 \\
(\mathrm{~N}=307)\end{array}$ & $\begin{array}{c}5.51 \\
(\mathrm{~N}=300)\end{array}$ & $\begin{array}{c}0.142 \\
(\mathrm{~N}=482)\end{array}$ & $\begin{array}{c}0.306^{\circ} \\
(\mathrm{N}=595)\end{array}$ \\
\hline \multicolumn{5}{|l|}{ Control variables } \\
\hline Personal income & & & yes & no \\
\hline Working hours & & & yes & no \\
\hline (Working hours) $^{2}$ & & & yes & no \\
\hline Education & & & yes & yes \\
\hline$(\text { Education })^{2}$ & & & yes & yes \\
\hline Age & & & yes & yes \\
\hline$(\text { Age })^{2}$ & & & yes & yes \\
\hline Gender & & & yes & yes \\
\hline
\end{tabular}

Notes: Numbers in the two left-hand columns are unweighted sample means; the two right-hand columns contain estimated coefficients on the variable "self-employed" from unweighted ordered-logit-regressions. The regressions "including compensating variables" are estimated including variables on personal work income (dummy variables for income categories or $\log$ (income), depending on the country), on average weekly hours worked and on hours worked squared. In the regressions "excluding compensating variables", these three variables are dropped from the analysis. This results in considerably larger sample sizes, as information on income is missing, particularly for many self-employed persons.

Significance levels: ${ }^{\circ} 0.1<\mathrm{p}<0.05, * 0.01<\mathrm{p}<0.05$, ** $\mathrm{p}<0.01$.

Data source: ISSP97, Module on "Work Orientations".

The results in table 1 show that self-employed people enjoy higher job satisfaction than employees in essentially all the 23 countries covered by the ISSP97. The raw differences indicate a positive relationship between self-employment and job satisfaction for every country, except for New Zealand, where the self-employed are slightly less happy with their jobs than employed persons (although not significantly so). The findings are confirmed in the regression analysis. Particularly for Western European and North American countries, positive and sizeable coefficients on the variable "self-employed" are found. Also in Eastern European and non-western countries, self-employment in general is associated with higher job satisfaction, but the estimated coefficients do not reach statistical significance in every case (the number of self-employed persons in the samples is often quite small). As factors like income or working hours are held constant in the first regression specification, it can be ruled out that differences in the material situation of self-employed and employed persons are responsible for the differences in job satisfaction. In general, the results confirm and, at the 
same time, extend the findings previously reported in the literature for European and North American countries (e.g. Blanchflower 2000, Frey and Benz 2003).

\subsection{Causes of higher job satisfaction among the self-employed}

In a next step of the empirical analysis, potential explanations for the observed selfemployment - job satisfaction relationship are examined. For that purpose, the variables on different work aspects described in the data section are used. It is tested how the coefficient on the self-employment variable changes when the individuals' evaluation of a particular job aspect is entered into the regression. As the ISSP97 includes seven such aspects, a separate analysis for every country would lead to a large set of results. The analysis is therefore conducted for groups of countries: Western European countries, North American countries, and Eastern European nations are pooled together, whereas "non-western" countries continue to be analyzed separately, because this residual category appears as too heterogeneous to form a single group. ${ }^{6}$

Table 2 gives an overview of the respective results. In the first column, a 'basic' coefficient on the self-employment variable is reported for each group of countries, estimated by an ordered-logit-regression, including a set of control variables (as in specification two above) and country fixed effects where appropriate. In accordance with the findings on single countries, a positive relationship between self-employment and job satisfaction is estimated for every geographical and cultural region. In the columns that follow, it is shown how the coefficient on the variable "self-employed" is affected when individuals' evaluations of the different work characteristics are included in the regression. These are, in turn, the assessments of the job dimensions "I can work independently", "my job is interesting", "my job is secure", "my income is high", "my opportunities for advancement are high", "in my job I can help other people" and "my job is useful to society".

\footnotetext{
${ }^{6}$ Moreover, the "non-western" country New Zealand is dropped from the analysis, as it is the only country where the self-employed are not more satisfied with their work than employed persons, and hence an analysis of job satisfaction differences cannot be sensibly made.
} 


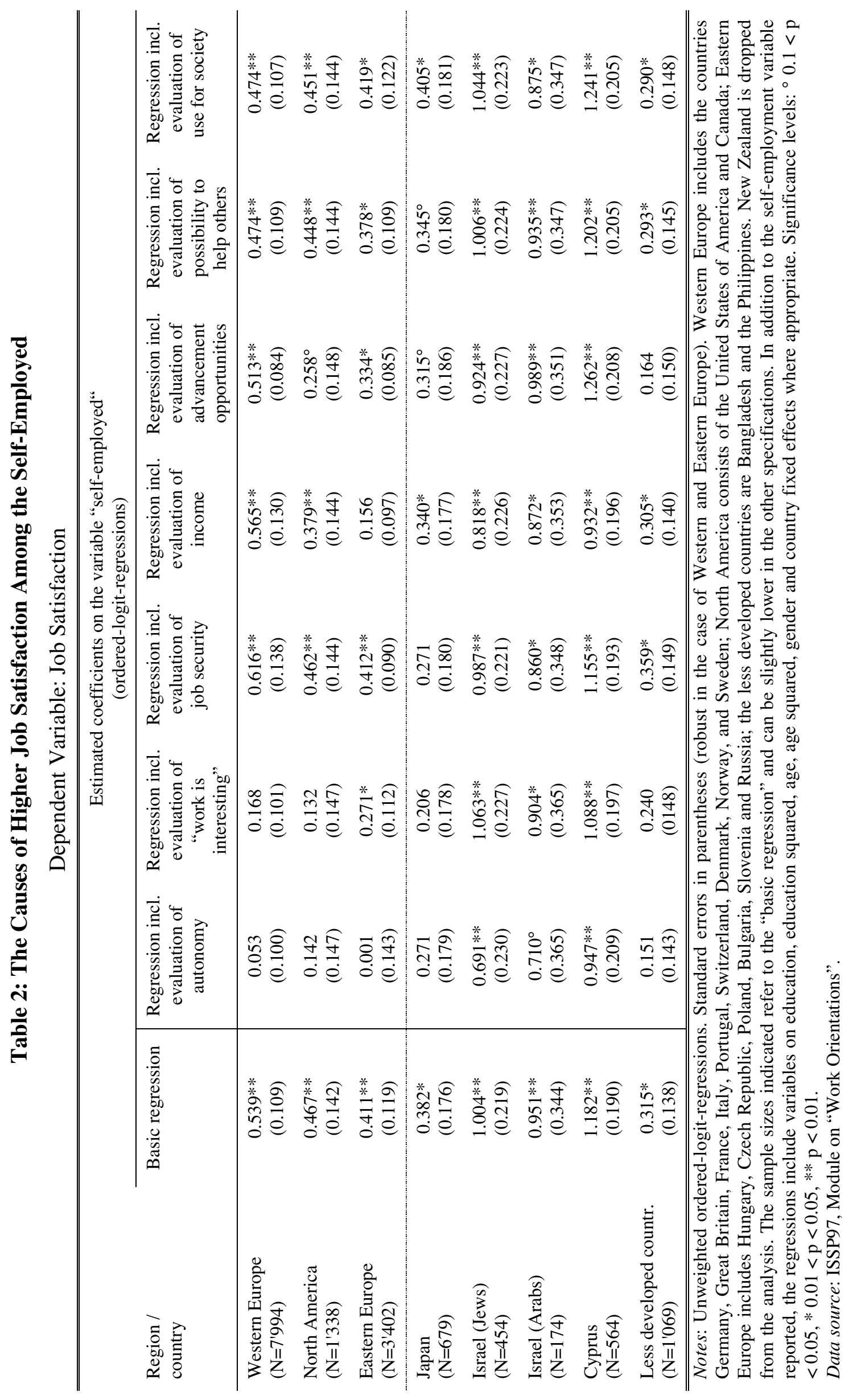


The results in table 2 clearly show that the higher job satisfaction of self-employed people can directly be attributed to the greater autonomy they enjoy, at least in western countries. In Western Europe, North America and Eastern Europe, the greater autonomy of the selfemployed fully explains the job satisfaction differential between self-employed and employed persons; when individuals" evaluation of the extent to which they "can work independently" is entered into the regression, the coefficient on the variable "self-employed" is lowered essentially to zero and loses statistical significance. To a considerable extent, also work perceived as more interesting accounts for the higher job satisfaction among the selfemployed. In contrast, other work dimensions like pay, job security or advancement opportunities seem not to be sufficiently different between the two groups to explain why the self-employed are happier with their jobs. The picture is somewhat more mixed for the residual group of "non-western" countries. Here, it is not possible to fully relate the selfemployment - job satisfaction effect to one of the work dimensions considered. Nevertheless, also in non-western countries like Japan, Israel, Cyprus and the less developed countries Bangladesh and the Philippines, perceived autonomy overall emerges as the work aspect that explains the higher job satisfaction among the self-employed the best.

\section{Discussion}

\subsection{The value of autonomy}

The results reported in the empirical section shed light on the well-documented fact that selfemployment is associated with particular benefits. Previous influential work has shown that the self-employed are e.g. prepared to work for lower wages in order to be self-employed (Hamilton 2000), or that they accept lower risk-adjusted returns on the entrepreneurial investments they make in their own firms (Moskovitz and Vissing-Jorgensen 2002). Here, for the first time, it is investigated in detail exactly what the nonpecuniary benefits of selfemployment consist of. ${ }^{7}$ Given that job satisfaction is a useful approximation for the utility from work, the findings indicate that the self-employed enjoy considerable utility from the opportunity of "being their own boss". The value of autonomy essentially explains the whole job satisfaction differential between self-employed and employed people, at least in western countries.

\footnotetext{
${ }^{7}$ Exceptions are Hundley (2001) and Frey and Benz (2003), see footnote 2.
} 
To our knowledge, the value of autonomy has never been documented empirically in the literature so far. The present study, however, suggests that it constitutes an important nonpecuniary work benefit. On the one hand, autonomy is appreciated because it is associated with the possibility of working independently. On the other hand, the self-employed also seem to enjoy considerable utility from their work, because they perceive their jobs as more interesting. This latter aspect is not necessarily in contradiction to the first; arguably, interesting work is strongly connected with autonomy of choice, in the sense that the selfemployed are freer to select tasks they find interesting, and that they can determine the variety of their tasks. Both aspects can probably be subsumed best under the term "selfdetermination".

In the theoretical economic literature, the value of autonomy has hardly been recognized so far. Autonomous decision-making is e.g. analyzed in studies in organizational economics (Williamson 1975, 1985, Aghion and Tirole 1997, Baker, Gibbons and Murphy 1999), but it is never taken into account that people might have a preference for autonomy in itself. Taking the nonpecuniary benefits of autonomy seriously, however, might enrich economic analysis also in the fields of organization and employment. ${ }^{8}$

\subsection{The existence of procedural utility}

In a broader context, the findings reported here can be interpreted as evidence for "procedural utility". Procedural utility means that people do not only care about instrumental outcomes, as is usually assumed in economics, but also value the processes and conditions leading to outcomes. It has been shown that procedural utility is an empirically relevant phenomenon in many areas of the economy, polity and society (Frey, Benz and Stutzer 2003). Selfemployment is related to the concept, because it reflects the difference between two fundamental decision-making procedures of the economy: whereas the self-employed are their own bosses and act as independent contractors on the market, employed persons are subject to the institution of hierarchy. The findings of this study suggest that self-employed people attach a substantial value to their independence, and not because it is associated with superior instrumental outcomes, like higher pay or lower working hours. Rather, autonomy is

\footnotetext{
${ }^{8}$ Williamson (1975: 39) e.g. concedes that issues such as the value of autonomy are neglected in his analysis of organizations. He refers to them by using the term "atmosphere": "Preferences for atmosphere may induce individuals to forego material gains for nonpecuniary satisfactions if the modes or practices are regarded as oppressive or otherwise repugnant. A full discussion of atmosphere and its ramifications raises a wider set of sociopolitical issues than can be addressed here."
} 
preferred because it is procedurally better than being subject to hierarchical decision-making, and is hence a source of procedural utility.

\subsection{Cultural differences}

Finally, the results presented in the empirical section can also give an indication of whether autonomy is valued differently in different cultures. In social sciences outside economics, it is often argued that autonomy of choice may be important to people in "individualistic" western cultures, like the United States, but not in more "collectivistic" non-western cultural contexts, like Asia (Iyengar and Lepper 1999, Schwartz 2000, Markus and Kitayama 1991). Experimental evidence supports this view. Iyengar and Lepper (1999) e.g. find that American individuals value the possibility of autonomously choosing between alternatives, whereas persons with an Asian cultural background often prefer that choices be made by others (especially by respected authorities). The analysis conducted here allows investigation of the issue in a non-experimental setting, where individuals are observed in their real work lives and arguably have substantial experience with either being independent or being employed in a hierarchical organization.

Our results show that the value of autonomy is in particular a western phenomenon, but not exclusively so. Self-employed persons are found to be more satisfied with their jobs in essentially all the countries considered, also in Asian countries like Japan, and in former communist countries of Eastern Europe, where great importance used to be attached to collectivist decision-making. The analysis moreover indicates that also in non-western countries, the higher job satisfaction of the self-employed is to a considerable extent based on the fact that individuals value the autonomy associated with self-employment. The results thus do not support a "culturalist" view. Rather, autonomy of choice seems to be of value to individuals in many cultures.

\subsection{Concluding Remarks}

In this paper, it has been shown that self-employed persons are more satisfied in their work than employees, mainly because they enjoy greater autonomy and independence. We submit that this might reflect a more general characteristic of human utility: individuals enjoy procedural utility from institutionalized procedures that allow for self-determination. The value of autonomy, moreover, seems not to be restricted to western, "individualistic" cultures. 


\section{References}

Aghion, Philippe and Jean Tirole (1997). Formal and Real Authority in Organizations. Journal of Political Economy 105(1): 1-29.

Baker, George, Robert Gibbons and Kevin J. Murphy (1999). Informal Authority in Organizations. Journal of Law, Economics and Organization 15(1): 56-73.

Blanchflower, David G. (2000). Self-Employment in OECD Countries. Labour Economics 7(5): 471-505.

Blanchflower, David G. and Andrew J. Oswald (1998). What Makes an Entrepreneur? Journal of Labor Economics 16(1): 26-60.

Finnie, Ross, Christine Laporte and Maud-Catherine Rivard (2002). Setting Up Shop: SelfEmployment Amongst Canadian College and University Graduates. Statistics Canada Research Paper Series, Working Paper No. 183.

Frey, Bruno S. and Matthias Benz (2003). Being Independent Is a Great Thing: Subjective Evaluations of Self-Employment and Hierarchy. CESifo Working Paper No. 959.

Frey, Bruno S., Matthias Benz and Alois Stutzer (2003). Introducing Procedural Utility: Not only What, but also How Matters. Journal of Institutional and Theoretical Economics, forthcoming.

Hamilton, Barton H. (2000). Does Entrepreneurship Pay? An Empirical Analysis of Returns to Self-Employment. Journal of Political Economy 108(3): 604-632.

Hundley, Greg (2001). Why and When Are the Self-Employed More Satisfied With Their Work? Industrial Relations 40(2): 293-317.

Iyengar, Sheena S. and Mark R. Lepper (1999). Rethinking the Value of Choice: A Cultural Perspective on Intrinsic Motivation. Journal of Personality and Social Psychology 76(3): 349-366.

Kawaguchi, Daiji (2002). Compensating Wage Differentials Among Self-Employed Workers: Evidence from Job Satisfaction Scores. Institute of Social and Economic Research, Osaka University, Discussion Paper No. 568.

Markus, Hazel R. and Shinobu Kitayama (1991). Culture and the Self: Implications for Cognition, Emotion, and Motivation. Psychological Review 98(2): 224-253.

Moskovitz, Tobias J. and Annette Vissing-Jorgensen (2002). The Returns to Entrepreneurial Investment: A Private Equity Premium Puzzle? American Economic Review 92(4): 745778.

Schwartz, Barry (2000). Self-Determination: The Tyranny of Freedom. American Psychologist 55(1): 79-88.

Williamson, Oliver E. (1975). Markets and Hierarchies: Analysis and Antitrust Implications. New York: Free Press.

Williamson, Oliver E. (1985). The Economic Institutions of Capitalism. Firms, Markets, Relational Contracting. New York: Free Press. 